\title{
Japan prepares to mark its independence in space...
}

Tokyo. Japan's space programme will enter a new era next week with the launch on Tuesday (1 February) of the first H-II rocket. This is a vehicle made entirely in Japan that will be able to compete with US and European rockets in terms of payload capability, and can be used to launch large Earth observation satellites.

The development of the H-II has been plagued with difficulties. Next week's launch is two years behind schedule because of setbacks in development of the liquid-fuel combustion engine in the first of its two stages; the engine burst into flames on several occasions during testing, and also killed an engineer during pressure tests of a component (see Nature 352; 651; 1991).

But if the launch is successful, Japan will have broken free of its dependency on US launcher technology, and will have a powerful launch vehicle capable of placing a twotonne satellite in geostationary orbit.

Japan is unusual in having two space organizations: the Institute of Space and Astronautical Science, operating under the Ministry of Education that launches small

\section{. . . as France and Germany end ESA dispute}

Paris. Determined to present a united face to its non-European partners in the international space station, the European Space Agency (ESA) last week ended a dispute between Germany and France over funding for their favoured manned space programmes by approving both programmes within a new single strategy.

A joint Franco-German team will now manage both the German-led Columbus programme - which includes the Attached Pressurized Module (APM) for the international space station Alpha, and flights by Europeans on the Russian Mir station and the French-led Manned Space Transportation Systems (MSTP) programme.

The latter is a revised version of the abandoned Hermes shuttle programme: it now includes the development of the launcher Ariane V and studies on an Apollolike capsule to be mounted on the nose of the launcher, a Euro-Russian space suit and a Dutch-built robotic arm.

The agreement breaks the deadlock over ESA's 1994-95 budget for manned space activities caused by disagreement between France and Germany over their contributions to each other's programmes. ESA's manned space programme will now get ECU477.4 billion (US\$540 milion) over the next two years, corresponding to ECU270.4 billion for Columbus and ECU207 billion for MSTP.

Formal approval of the budget will depend, however, on the successful outcome of a separate dispute over ESA's financial mechanisms at a meeting of council next Monday (31 January). Both Italy and Spain will seek redress for increases in their subscription fees due to a recent decline in the value of their respective currencies.

The endorsement of a common strategy by ESA's member states - including Italy and Spain, which some had feared might withdraw support - will alleviate a period of uncertainty over Europe's space station plans, says Jean-Daniel Levy, the directorgeneral of the French space agency CNES.

Levy says that, with the United States and Russia now committed to an international space station, "we have a much clearer idea of where we going than last year". Jim Thomas, deputy director of the British National Space Centre, agrees that the situation has stabilized. But he points out that ESA's plans remain at the mercy of uncertainty in the United States and Russia over the shape of the space station.

Some still fear that if the station falls through, ESA will be left with a costly programme it does not need. ESA argues that its revised plans could enable it to build its own orbiting laboratory; but many believe this argument is more a negotiating weapon than a serious proposition.

Furthermore, ESA's contributions to the space station will hang in the balance until formally endorsed at next year's meeting of the space ministers of its member states. The economic recession in Europe, and falling interest in space in many European countries, could lead to yet another round of cuts in the manned space programme.

ESA also faces a series of medium-term threats. The agency already accounts for less than half of Europe's space activities; indeed its budget is less than that of the French space agency CNES. Mark Gidget of the Paris-based space consultancy Euroconsult says that most advanced European countries have expressed a preference for working alone or directly with the United States or Russia. If interest drops in the agency's big programmes, "its raison d'être will disappear", he says.

The biggest threat to ESA in the long term is European political union, says Gidget. The Maastricht treaty has extended the European Commission's role in science and defence, and observers say it is bent on gaining control of space programmes.

Declan Butler

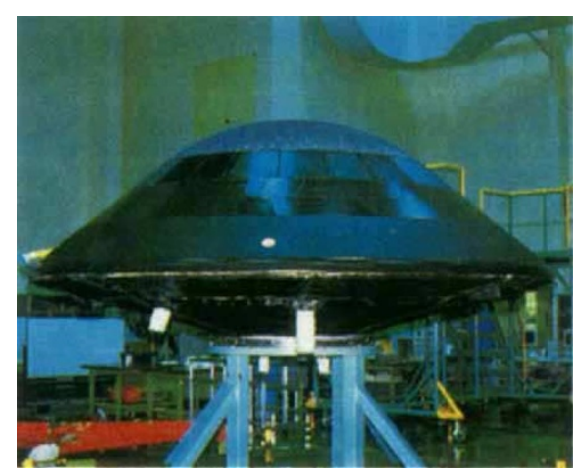

Japan's Orbital Reentry Experiment Vehicle (OREX) will be one of HH's first payloads.

scientific payloads with Japanese-developed solid fuel rockets; and the National Space Development Agency (NASDA), affiliated to the Science and Technology Agency, which launches larger Earth observation and communications satellites and has until now been using US technology in its launch vehicles.

The H-II will be used to launch at least two large Earth observation satellites this decade that will carry US and European as well as Japanese sensors. One, the Advanced Earth Observing Satellite (ADEOS), is scheduled for launch in 1996, and will have ozone sensors and other equipment for monitoring the Earth's environment.

The Tropical Rainfall Monitoring Mission, a joint project with the US National Aeronautics and Space Administration, will be launched a year later to observe clouds and rainfall in tropical regions. A second ADEOS satellite is tentatively scheduled for launch at the end of the decade.

Although Japan can now compete with US and European rockets such as Ariane in terms of payload capability, it remains to be seen if the H-II can break into the lucrative commercial market for the launch of communications satellites.

Rocket Systems Corporation, a consortium of 75 Japanese companies, has been set up to bid for orders for launches from organizations such as the International Telecommunications Satellite Organization (see Nature 352, 651; 1991). But the H-II is at present limited to two short launch windows a year under an agreement with local fishermen at NASDA's launch site in Tanegashima island. Furthermore, the price of H-II launches is higher than that of competitors.

Early in the next decade, NASDA is planning to use the $\mathrm{H}$-II for launches of an unmanned space shuttle called HOPE (H-II Orbiting Plane) now under development. This will be capable of carrying payloads of several tonnes into low Earth orbit, and may be used to transport equipment to and from the US Space Station Freedom.

The H-II launch next week will carry an orbital re-entry test vehicle, resembling the nose cone of HOPE. It will be placed in orbit, return to Earth and splash down by parachute in the Pacific Ocean a few hours after launch.

David Swinbanks 